Acta Cryst. (1954). 7, 591

\title{
Variation of Unit-Cell Dimensions of a Crystal Form of Long Normal Ghain Carboxylic Acids
}

\author{
By Sixten Abrahamsson and ErIK von Sydow \\ Institute of Chemistry, University of Uppsala, Uppsala, Sweden
}

(Received 15 April 1954)

\begin{abstract}
The unit cells of form $C$ of long normal chain carboxylic acids with 12, 14, 18, 22 and 26 carbon atoms are determined, using powder methods. All dimensions in the monoclinic cell are found to be dependent of the number of carbon atoms in the chain. The $a$ and $b$ axes and the angle $\beta$ decrease asymptotically with increasing chain length. The $c$ axes and long spacings, $d(001)$, obey linear laws.
\end{abstract}

\section{Introduction}

This work was carried out in connexion with crystalstructure investigations of long normal chain carboxylic acids.

Vand, Aitken \& Campbell (1949) found that all the unit-cell dimensions of silver soaps changed with chain length. In order to find the behaviour of the unit-cell dimensions of a crystal form of long normal chain carboxylic acids the unit cells of form $C$ of several acids with an even number of carbon atoms were determined, using powder methods. The crystal structure of form $C$ of lauric acid has been determined by Vand, Morley \& Lomer (1951). The unit cell is monoclinic with four molecules in the cell. The hydrocarbon chains have the orthorhombic packing determined by Bunn (1939) and Vainshtein \& Pinsker (1950). Unitcell determinations of this form have been made by Thibaud \& Dupré la Tour (1932) (palmitic acid) and by Trillat \& v. Hirsch (1932) (stearic acid).

\section{Preparation of specimens}

Very pure acids with $12,14,18,22$ and 26 carbon atoms were obtained from Prof. E. Stenhagen and his collaborators. The melting points are: $44 \cdot 5-44 \cdot 8,54 \cdot 2-$ $54 \cdot 5,69 \cdot 6,79 \cdot 6-79 \cdot 8$ and $87 \cdot 6-87 \cdot 7^{\circ} \mathrm{C}$.

According to Stenhagen \& von Sydow (1953), form $C$ of even acids is obtained from the melt and from polar solvents.

Specimens were crystallized from the melt and from ethanol by precipitation with water. Form $C$ of myristic acid $\left(\mathrm{C}_{14}\right)$ was also obtained in large crystals from slowly evaporating light petroleum.
Scotch tape was used as support for the plane powder samples. From the melt the acids were crystallized directly on the tape to avoid mechanical deformation. The dried powder obtained from ethanol was cautiously pressed on the tape. The crystals of myristic acid $\left(\mathrm{C}_{14}\right)$ were cut with a razor to a fine powder.

\section{X-ray work}

The powder photographs were taken in a Guinier camera using $\mathrm{Cu} K \alpha$ radiation. In order to avoid errors due to film-shrinkage a method described by Hägg (1947) was used. The camera was calibrated five times with $\mathrm{NaCl}$.

\section{Unit-cell determination}

Lauric acid was indexed first, using the single crystal data of Vand, Morley \& Lomer (1951). From these data it can be seen that reflexions having $|l|=14$ are generally strong. This is due to the periodicity in the hydrocarbon chains. The other acids were supposed to have analogous strong reflexions with $|l|=n+2$, which proved to be true. With this indexing the cell dimensions of all investigated acids could be determined. The data are found in Table 1 and Fig. 1, together with earlier published values.

\section{Results}

The cell dimensions are independent of the mode of preparation within experimental error, but all dimensions change continuously with chain length. The $a$

Table 1. Unit-cell dimensions

$\begin{array}{cccccc}n & \begin{array}{c}a(\AA) \\ ( \pm 0 \cdot 020 \AA)\end{array} & \begin{array}{c}b(\AA) \\ ( \pm 0 \cdot 004\end{array} & \begin{array}{c}c(\AA) \\ ( \pm 0 \cdot 08 \AA)\end{array} & \begin{array}{c}d(001)(\AA) \\ ( \pm 0.04 \AA)\end{array} & \begin{array}{c}\beta \\ \left( \pm 6^{\prime}\right)\end{array} \\ 12 & 9 \cdot 634 & 4 \cdot 966 & 35.58 & 27 \cdot 43 & 129^{\circ} 35^{\prime} \\ 14 & 9 \cdot 509 & 4 \cdot 968 & 40.71 & 31 \cdot 58 & 129^{\circ} 7^{\prime} \\ 18 & 9 \cdot 357 & 4 \cdot 956 & 50 \cdot 76 & 39 \cdot 87 & 128^{\circ} 14^{\prime} \\ 22 & 9 \cdot 292 & 4 \cdot 953 & 60 \cdot 87 & 48 \cdot 22 & 127^{\circ} 37^{\prime} \\ 26 & 9 \cdot 249 & 4 \cdot 954 & 71 \cdot 18 & 56 \cdot 63 & 127^{\circ} 19^{\prime} \\ \infty & 9 \cdot 21 & 4 \cdot 95 & - & - & 127^{\circ} 17^{\prime}\end{array}$




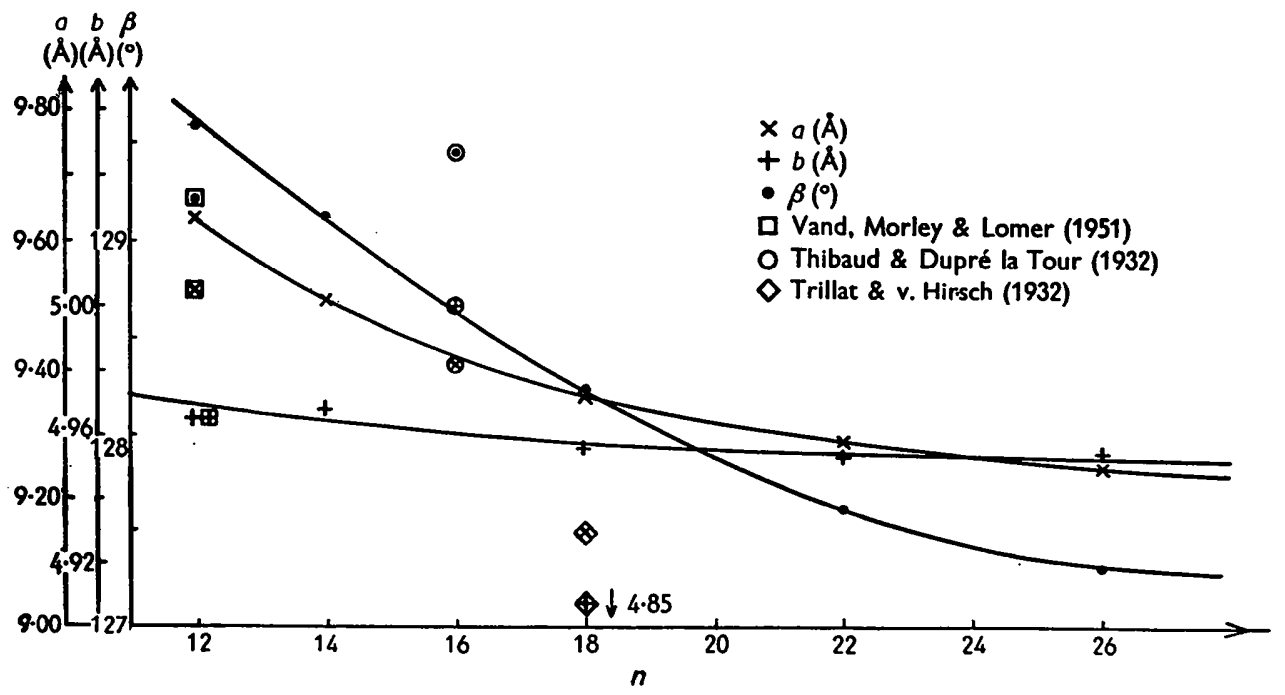

Fig. 1. Unit-cell dimensions of form $C$ of normal fatty acids.

and $b$ axes are found to decrease, having asymptotic values of $9.21 \AA$ and $4.95 \AA$ respectively. The monoclinic angle $\beta$ decreases towards $127^{\circ} 17^{\prime}$. The $c$ axes and long spacings, $d(001)$, are linear functions of the carbon content within experimental error:

$$
\begin{array}{ll}
c=p n+q, & d(001)=P n+Q, \\
p=2 \cdot 5378 \pm 0 \cdot 0042 \AA, & P=2 \cdot 0850 \pm 0 \cdot 0024 \AA, \\
q=5 \cdot 124 \pm 0 \cdot 080 \AA, & Q=2 \cdot 383 \pm 0 \cdot 044 \AA .
\end{array}
$$

The constants are determined by the method of least squares.

Vand, Aitken \& Campbell (1949) pointed out that long-chain compounds are only 'approximately homologous', and this is obviously the case with this form and likely also with the other crystal forms of normal fatty acids.

We are indebted to Prof. G. Hägg and Prof. E. Sten- hagen for their interest and to Mr N. O. Bodin for help with the calculations.

\section{References}

BonN, C. W. (1939). Trans. Faraday Soc. 35, 482.

HÄGG, G. (1947). Rev. Sci. Instrum. 18, 371.

Stenhagen, E. \& Sxdow, E. von (1953). Ark. Kemi, 6, 309.

Thubaud, J. \& Dupré In Tour, F. (1932). J. Chim. phys. 29, 164.

Trmlat, J. J. \& Hirsch, Th. v. (1932). C. R. Acad. Sci., Paris, 195, 215.

Vannshtein, B. K. \& Pinsker, Z. G. (1950). Dokl. Akad. Nauk, SSSR. 72, 53.

VAND, V., Attken, A. \& Campbeil, R. K. (1949). Acta Cryst. 2, 398.

VAND, V., MoRLeY, W. M. \& Lomer, T. R. (1951). Acta Cryst. 4, 324.

\section{Short Communications}

Contributions intended for publication under this heading should be expressly so marked; they should not exceed about 500 words; they should be forwarded in the usual way to the appropriate Co-editor; they will be published.as speedily as possible; and proofs will not generally be submitted to authors. Publication will be quicker if the contributions are without illustrations.

Acta Cryst. (1954). 7, 592

Electron diffraction by electropolished surfaces and mean inner potentials of silver and copper. By Susumu YosHma, The Government Mechanical Laboratory, Suginami-ku, Tokyo, Japan

(Received 25 March 1954)

Electropolished surfaces of metal single crystals are almost flat, and only slightly undulating. An undulating surface is composed of minute facets which form small angles with the macroscopic surface. From electron- diffraction data, Kranert, Leise \& Raether (1944) estimated the angle to be $1-2^{\circ}$ for an electropolished copper single crystal. However, they had to assume a certain value for the mean inner potential of the copper crystal. 